\title{
ATTENUATION OF LIVER CANCER DEVELOPMENT BY ORAL GLYCEROL SUPPLEMENTATION IN THE RAT
}

Alejo M Capiglioni ${ }^{\mathrm{a}}$, Florencia Lorenzetti ${ }^{\mathrm{a}}$, Ariel D Quiroga ${ }^{\mathrm{a}}$, , Juan P Parody ${ }^{\mathrm{a}}$, María T Ronco $^{\text {a }}$, Gerardo B Pisani ${ }^{\mathrm{b}}$, María C Carrillo ${ }^{\mathrm{a}}$, b, María P Ceballos ${ }^{\mathrm{a}}$, María de Luján Alvarez $^{\mathrm{a}, \mathrm{b}}$

a Instituto de Fisiología Experimental (IFISE), Facultad de Ciencias Bioquímicas y Farmacéuticas, CONICET, UNR, Suipacha 570 (S2002LRL) Rosario, Argentina

b Área Morfología, Facultad de Ciencias Bioquímicas y Farmacéuticas, UNR, Suipacha 570 (S2002LRL) Rosario, Argentina

Corresponding author: María de Luján Alvarez, Ph.D. Instituto de Fisiología Experimental (IFISE), Facultad de Ciencias Bioquímicas y Farmacéuticas, CONICET, UNR. Suipacha 570 (S2002LRL) Rosario, Argentina. E-mail: alvarez@ifise-conicet.gov.ar; Tel: +54 341 4305799; Fax: +54 3414399473 


\section{Acknowledgments:}

This work was supported by research grants PICT $2013 \mathrm{~N}^{\circ} 1693$ (Alvarez) from Agencia Nacional de Promoción Científica y Tecnológica and by PIP $N^{\circ} 0062$ (Carrillo and Alvarez) from Consejo Nacional de Investigaciones Científicas y Técnicas.

The authors thank Wiener Lab for the generous gift of critical reagents for glycerol phosphate enzymatic determination and Dr. Mauricio Rassetto for his expert technical assistance in performing this procedure. 


\section{Abstract}

2 Purpose: glycerol usage is increasing in food industry for human and animal nutrition. This

3 study analyzed the impact of glycerol metabolism when orally supplemented during the

4 early stage of rat liver carcinogenesis.

5 Methods: Wistar rats were subjected to a 2-phase model of hepatocarcinogenesis (initiated-

6 promoted, IP group). IP animals also received glycerol by gavage $(200 \mathrm{mg} / \mathrm{Kg}$ body

7 weight, IPGly group).

8 Results: glycerol treatment reduced the volume of preneoplastic lesions by decreasing the

9 proliferative status of liver foci, increasing the expression of p53 and p21 proteins and

10 reducing the expression of cyclin D1 and cyclin-dependent kinase 1. Besides, apoptosis was

11 enhanced in IPGly animals, given by an increment of Bax/Bcl-2 ratio, Bad and PUMA

12 mitochondrial expression, a concomitant increase in cytochrome c release and caspase-3

13 activation. Furthermore, hepatic levels of glycerol phosphate and markers of oxidative

14 stress were increased in IPGly rats. Oxidative stress intermediates act as intracellular

15 messengers, inducing p53 activation and changes in JNK and Erk signaling pathways, with

16 JNK activation and Erk inhibition.

17 Conclusion: the present work provides novel data concerning the preventive actions of 18 glycerol during the development of liver cancer and represents an economically feasible intervention to treat high-risk individuals.

20

21 Keywords: proliferation; apoptosis; glycerol; liver preneoplasia; oxidative stress 


\section{Introduction}

25 Glycerol (propane-1,2,3-triol) is a viscous, colorless and odorless liquid, with sweet taste

26 and completely soluble in water and alcohols. Because of its physicochemical properties

27 glycerol is used in a great number of commercial products including cosmetics, personal

28 care products, pharmaceutical formulations, foods and beverages [1, 2]. Glycerol use is

29 increasing in food industry. Since it gives sweet taste but it does not induce insulin

30 secretion during digestion, glycerol is commonly used as an artificial sweetener, especially

31 in low-fat foods. Glycerol is also used as a thickening agent and a preserving additive in a

32 variety of comestible products [3]. Besides, it has been proposed the use of glycerol as a

33 food supplement in animal diets and it has also been used for rehydration or exercise

34 performance in animals and even humans [4, 5]. Toxicity data for oral glycerol

35 administration indicate that it is safe, with infrequent side effects [6].

36 In clinical practice, glycerol has been used as an osmotic adjuvant for controlling

37 intracranial pressure [7]. It has also been reported that glycerol inhibits in vitro proliferation

38 in various cell types [8] and decreases the cerebral growth of neonatal rabbits [9]. In the

39 liver, glycerol has a potent growth-inhibitory effect in vivo during regeneration after partial

40 hepatectomy and in vitro in mitogen-induced hepatocyte cultures as well as in a human

41 HCC cell line [10]. However, the mechanisms involved in the antiproliferative actions of

42 glycerol have not been deeply explored.

43 Hepatocellular carcinoma $(\mathrm{HCC})$ is one of the most lethal tumors worldwide and its

44 prognosis largely depends on tumor stage at the moment of diagnosis. Incidence of HCC

45 has continuously increased over the last years and improved surveillance could be

46 associated with identifiable high-risk patients, like those with chronic liver disease 
47 originated from viral infections, high alcohol consumption or non-alcoholic steatohepatitis,

48 among others [11]. In these patients, liver preneoplastic foci of altered hepatocytes emerge

49 months or years before the diagnosis of HCC [12]. Similar preneoplastic lesions are found

50 in rodents during early stages of liver cancer induced by chemicals [13].

51 In the present study, we analyzed whether oral administration of glycerol during the early

52 stage of rat liver carcinogenesis is capable of reducing preneoplastic foci development. We

53 also attempt to elucidate the molecular mechanisms associated with this phenomenon.

54

552 Materials and Methods

56

$57 \quad 2.1$ Reagents and Chemicals

58 Diethylnitrosamine (DEN), 2-acetylaminofluorene (2-AAF) and glycerol were obtained

59 from Sigma Chemical Co. (St. Louis, MO, USA). Anti-pi class of rat glutathione S-

60 transferase (rGST P) was from Stressgen Bioreagents (Ann Arbor, MI, USA). Cy3

61 fluorescent secondary antibody was purchased from Jackson ImmunoResearch

62 Laboratories, Inc. (West Grove, PA, USA). Antibodies against proliferating cell nuclear

63 antigen (PCNA), p53, p21, cyclin D1, cyclin E, cyclin A, cyclin B1, cdk1 (cyclin-

64 dependent kinase 1), cdk2, Bax, Bcl-2, Bad, PUMA $\alpha / \beta$, cytochrome c, p-Akt (Ser473), and

65 Akt were from Santa Cruz Biotechnology (Santa Cruz, CA, USA). Anti-p-JNK 1/2/3

66 (Thr183/Tyr185), anti-JNK1/2/3 (against JNK 1 and 2/3 isoforms), anti-p-Erk1/2

67 (Thr202/Tyr204) anti-Erk1/2 (against Erk 1 and 2 isoforms) antibodies were purchased

68 from Cell Signaling Technology (Danvers, MA, USA). Pierce enhanced

69 chemiluminescence (ECL) Western Blotting Substrate was from Thermo Fisher Scientific 
70 (Rockford, IL, USA). All other chemicals were of the highest grade commercially 71 available.

$73 \quad 2.2$ Animals and treatment

74 Experimental protocols were performed according to the NIH "Guide for the Care and Use 75 of Laboratory Animals" (Publication no. 25-28, revised 1996) and approved by the local 76 animal care and use committee (Permission 6060/234, FBioyF, UNR). Adult male Wistar 77 rats were subjected to a 2-phase (initiation-promotion) model of hepatocarcinogenesis, as 78 previously described [14]. All animals received 2 necrogenic doses of DEN (150 mg/Kg 79 body weight, intraperitoneally) 2 weeks apart (initiation phase). The promotion stage began 80 one week after the last injection of DEN; all rats received 2-AAF (20 mg/Kg body weight) 81 by gavage 4 consecutive days per week during 3 weeks. Before the start of the initiation82 promotion treatment, animals were divided into two goups of six rats each: IP group, 83 animals received the carcinogenic treatment plus a saline solution (glycerol vehicle); and 84 IPGly group, they received the carcinogenic treatment plus $200 \mathrm{mg} / \mathrm{Kg}$ body weight 85 glycerol administered by gavage once a week, 2 hs before DEN or 2-AAF treatment. A 86 scheme of the experimental protocol is shown in Supplementary Figure 1. Animals were 87 anesthetized with ketamin/ xylazine (100 and $3 \mathrm{mg} / \mathrm{Kg}$ body weight, respectively) and 88 sacrificed by exsanguination at the end of the sixth week. Blood samples were collected 89 and livers were removed and processed.

90

\section{$91 \quad 2.3$ Serum free glycerol and enzymes activities determination}


92 Serum free glycerol was determined in serum samples using Free Glycerol Determination

93 Kit (Sigma Chemical Co.). Alanine and aspartate aminotransferases (ALT and AST, 94 respectively) and alkaline phosphatase (ALP) were determined spectrophotometrically in 95 fresh serum by commercial kits (Wiener Lab, Rosario, Argentina).

96

$97 \quad 2.4$ Immunofluorescence detection and quantitation of rGST P-positive preneoplastic 98 foci

99 Immunohistochemical detection of rGST $\mathrm{P}$ is the chosen method for identification and 100 quantification of preneoplastic foci [15]. Immunofluorescent detection of rGST P-positive 101 foci was performed as previously described [16]. Images were analyzed using ImageJ 102 software (U. S. National Institutes of Health, Bethesda, MD, USA). The number of 103 preneoplastic foci per liver and the percentage of liver occupied by foci were calculated 104 according to the modified Saltykov's method [17].

105

106

\subsection{PCNA detection and proliferative index determination}

107 Immunohistochemical staining of PCNA protein was performed following the method of 108 Greenwell et al. [18]. Proliferative cells inside the foci and in the surrounding tissue were 109 distinguished by analyzing consecutive section slides stained with anti-rGST P. The PCNA 110 proliferative index was defined as the number of proliferative cells (in $\mathrm{G}_{1}, \mathrm{~S}, \mathrm{G}_{2}$ and $\mathrm{M}$

111 phases) per 100 hepatocytes counted in 10 high-power fields. Preneoplastic hepatocytes in 112 each phase of the cell cycle were also determined by a blinded histologist, using specific 113 PCNA staining patterns, as previously described [16, 19]. Data were expressed as 114 percentage of preneoplastic cells in each stage of the cell cycle. 


\section{$116 \quad 2.6$ Western blot analysis}

117 Whole liver samples were homogenized in $300 \mathrm{mM}$ sucrose with protease and phosphatase

118 inhibitors. Cytosolic, mitochondrial and nuclear extracts were prepared as previously 119 described [14, 16]. Equal amounts of protein were subjected to electrophoresis on $12 \%$ 120 SDS-polyacrylamide gels and transferred onto polyvinyl difluoride membranes 121 (PerkinElmer Life Sciences, Boston, MA, USA). Membranes were blocked, washed and 122 incubated overnight at $4{ }^{\circ} \mathrm{C}$ with primary antibodies. Finally, membranes were incubated 123 with peroxidase-conjugated secondary antibodies and bands were detected by the ECL 124 detection system and quantified by densitometry using the Gel-Pro Analyzer software 125 (Media Cybernetics, Silver Spring, MD, USA). Equal loading and protein transference 126 were checked by Ponceau S staining of the membranes.

$128 \quad 2.7$ Caspase-3 activity assay

129 Caspase-3 activity was determined using EnzChek Caspase-3 Assay Kit \#1 (Molecular 130 Probes Inc, Eugene, OR, USA), according to the manufacturer's suggestions.

\section{$132 \quad 2.8$ Determination of hepatic glycerol phosphate content}

133 Glycerol phosphate in liver homogenates was enzymatically measured as previously 134 described [20], with slight modifications. First, glycerol phosphate was oxidized by 135 glycerol-3-phosphate oxidase, to generate hydrogen peroxide and dihydroxyacetone 136 phosphate; and second, peroxidase catalyzed the coupling of hydrogen peroxide with 4- 
137 aminophenazone and chlorophenol to produce a quinoneimine dye that can be measured at

$138540 \mathrm{~nm}$. Glycerol standard solution (Wiener Lab) was used as negative control.

\subsection{Lipid peroxidation assay}

141 Lipid peroxidation is considered as an indirect measure of reactive oxygen species (ROS)

142 generation [21]. The amount of aldehydic products generated by lipid peroxidation in liver

143 homogenates was quantified by the thiobarbituric acid reaction according to the method of 144 Ohkawa et al. [22] and measured by high-performance liquid chromatography.

$146 \quad 2.10$ Liver tissue antioxidant capacity analysis

147 Reduced (GSH) and oxidized (GSSG) glutathione were determined in total liver 148 homogenates according to the protocol described by Tietze [23], and GSH/GSSG ratio was 149 calculated. Superoxide dismutase (SOD) gel activity assay was based on the method of 150 Donahue et al. [24]. Bands quantification was made by densitometry using the Gel-Pro 151 Analyzer software. Catalase (CAT) activity was determined by monitoring the rate of $\mathrm{H}_{2} \mathrm{O}_{2}$ 152 decomposition as a function of absorbance decrease at $240 \mathrm{~nm}$ [25].

\section{$154 \quad 2.11$ Determination of protein concentration}

155 Protein concentration was determined by the Lowry method [26], using bovine serum 156 albumin as a standard.

157

\subsection{Statistical analysis}


Results were expressed as mean \pm SEM. Significance in differences was tested by Student's t-test. Differences were considered significant when the $p$ value was $<0.05$.

\section{Results}

\subsection{Serum free glycerol levels and hepatic enzymes activities did not change after oral} administration of glycerol

Oral administration of glycerol had no effect on serum free glycerol levels measured at the end of the experimental protocol (IP: $0.55 \pm 0.06 \mathrm{~g} / \mathrm{L}$; IPGly: $0.54 \pm 0.04 \mathrm{~g} / \mathrm{L}$ ), as it is rapidly absorbed in the gastrointestinal tract and cleared from blood.

On the other hand, serum markers of liver damage ALT, AST and ALP showed no statistical differences between groups (data not shown).

\subsection{Oral administration of glycerol affected the volume of preneoplastic foci}

Fig. 1a shows representative images from IP and IPGly groups. Oral administration of 200 $\mathrm{mg} / \mathrm{Kg}$ body weight glycerol did not induce significant changes in the number of liver foci. However, the percentage of liver occupied by foci significantly decreased in IPGly group as compared to IP animals (Fig. 1b).

\subsection{Proliferative status of liver foci was modified by glycerol treatment}

Representative images of PCNA staining from the experimental groups are shown in Fig. 2a. Glycerol administration induced a significant decrease of the proliferative index inside 
181 the foci. However, glycerol treatment did not affect the proliferative status of the tissue 182 surrounding the preneoplastic foci (Fig. 2b).

183 Furthermore, we analyzed the percentages of preneoplastic hepatocytes in each phase of the 184 cell cycle (Fig. 2c). Glycerol administration induced a significant increase in the percentage 185 of cells in $G_{1}$ phase of the cell cycle along with a significant decrease in the percentage of 186 cells in $\mathrm{M}$ phase.

\subsection{Glycerol affected the expression of cell cycle-related proteins}

189 Western blot studies revealed significant increases in the cell cycle-regulatory proteins p53 190 and p21 in preneoplastic livers of animals treated with glycerol (Fig. 3a and b, 191 respectively). In addition, protein levels of cyclin D1 (Fig. 3c) and cyclin-dependent kinase 1921 (cdk1, Fig. 3h) were significantly decreased in IPGly group. Glycerol administration had 193 no effect on cyclins E, A and B neither on cdk2 (Fig. 3d, e, f and g).

\subsection{Glycerol administration induced programmed cell death in preneoplastic livers}

196 Oral administration of glycerol significantly enhanced caspase-3 activity (Fig. 4a), which 197 indicated that programmed cell death was occurring. Also, pro-apoptotic Bax levels were 198 increased whereas anti-apoptotic Bcl-2 levels were decreased in liver mitochondrial 199 fractions of IPGly group (Fig. 4b). Accordingly, Bax/Bcl-2 ratio was significantly 200 augmented in animals that received glycerol (Fig. 4c). In addition, mitochondrial levels of 201 pro-apoptotic proteins Bad and PUMA were increased in IPGly animals (Fig. 4d and e). 202 Finally, the release of cytochrome c into the cytosol was increased in IPGly group (Fig. 4f). 
205 The first stage in hepatic glycerol metabolism is the conversion into glycerol phosphate by 206 glycerol kinase [27]. Fig. 5 shows that hepatic glycerol phosphate levels were increased in 207 IP animals upon oral administration of glycerol.

\subsection{Lipid peroxidation and antioxidant capacity were modified by glycerol} administration

211 It has been reported that mitochondrial metabolism of glycerol phosphate generates ROS 212 intermediates [28, 29]. Therefore, we analyzed the amount of thiobarbituric acid reactive 213 substances (TBARS) as a reflection of the hepatic oxidative status. As shown in Fig. 6a, 214 glycerol administration produced a significant increase in TBARS levels compared to IP 215 group. Also, no significant changes in GSH/GSSG ratio were observed between treatments 216 (Fig. 6b). On the other hand, Cu/Zn SOD activity was significantly increased (Fig. 6c) and 217 CAT activity was significantly decreased (Fig. 6d) in IPGly animals. As SOD catalyzes 218 superoxide radical dismutation into $\mathrm{O}_{2}$ and $\mathrm{H}_{2} \mathrm{O}_{2}$ and CAT catalyzes the decomposition of $219 \mathrm{H}_{2} \mathrm{O}_{2}$ to $\mathrm{O}_{2}$ and $\mathrm{H}_{2} \mathrm{O}$, it is likely that $\mathrm{H}_{2} \mathrm{O}_{2}$ is mainly produced during the treatment of IP 220 animals with oral glycerol.

221

\subsection{Glycerol affected JNK1/2/3 and Erk2 activation in preneoplastic livers}

223 Previous studies have shown that pyruvate metabolism produces mitochondrial oxidants 224 release which mediate c-Jun N-terminal kinase (JNK) activation [30]. Since glycerol shares 225 structural and metabolic similarities with pyruvate, we analyzed if oxidative stress 226 generation by glycerol metabolism in IPGly animals was able to activate JNK signaling. 
Additionally, we studied extracellular-signal-regulated kinase (Erk) and protein kinase Akt activation, which are critical kinases involved in cell proliferation and apoptosis usually deregulated in HCC [31]. The levels of total and activated (phosphorylated) kinases in liver homogenates were measured by western blot and the phosphorylated/total kinase ratios were calculated. As seen in Fig. 7a, there was a significant increase in the p-JNK/JNK ratio (for the three isoforms) in glycerol-treated animals. In addition, there was a significant diminution in the p-Erk2/Erk2 ratio, with no changes in the activation of Erk1 isoform in IPGly group (Fig. 7b). Finally, p-Akt/Akt ratio showed no differences between the experimental groups (Fig. 7c).

\section{Discussion}

In the present study we tested the potential antiproliferative effect of oral glycerol supplementation in early liver carcinogenesis and also explored the mechanisms by which glycerol exerts such effect.

The selected dose was based in a previous study in rats which evaluated the effect of oral pure glycerol as a food supplement [4]. We observed that serum markers of liver function did not change in IP animals treated with $200 \mathrm{mg} / \mathrm{Kb}$ body weight glycerol, in accordance with the unaffected metabolic parameters previously reported. Furthermore, we used an intermittent regimen of administration, as previously reported for quercetin in our experimental model of liver preneoplasia [16].

The analysis of number and size of proliferative lesions clearly showed that glycerol administration induces a reduction in the development of liver foci, without affecting the number of initiated cells that clonally expand to generate preneoplastic lesions, but 
reducing the growth rate of these clones instead. Accordingly, the study of the proliferative

251 status of liver foci indicates that a lower number of hepatocytes are entering into the cell

252 cycle in glycerol-treated rats. Our results show that glycerol action seems to be specific for

253 preneoplastic hepatocytes. Experiments in control (non IP) rats showed that glycerol

254 administration did not affect serum liver damage markers, it kept normal hepatic

255 architecture and it did not affect PCNA staining (data not shown), showing that glycerol

256 exerts its actions in hepatocytes primed to proliferate rather than in quiescent liver cells, in

257 line with previous findings on regenerating rat livers [10].

258 Induction of p53 results in increased p21 protein levels, a critical regulator of cell cycle

259 arrest [32]. Although we did not deepen the study of the mechanisms involved in p53 and

260 p21 activation, the increased expression of these proteins in liver tissue of IPGly animals

261 support both the antiproliferative and the proapoptotic phenomena observed in this

262 experimental group. The decrease in cyclin D1 protein levels in glycerol-treated rats is in

263 line with the accumulation of preneoplastic cells in $\mathrm{G}_{1}$ phase. We have also observed that

264 glycerol produces a clear decrease in mitosis, most likely induced by the decrease of cdk1

265 protein, a fact that does not favor cyclin $\mathrm{B} / \mathrm{cdk} 1$ complex formation necessary for the cell to

266 enter into the M phase of cell cycle.

267 Dysregulation of the balance between proliferation and apoptosis defines a pro-tumorigenic 268 basis in hepatocarcinogenesis [33]. Consequently, targeting one or both of these features 269 may result in a reduced tumor development. In this context, increased caspase-3 activity in 270 IPGly animals indicates that apoptosis is enhanced after treatment. Furthermore, glycerol 271 increases mitochondrial $\mathrm{Bax} / \mathrm{Bcl}-2$ ratio and $\mathrm{Bad}$ and PUMA pro-apoptotic proteins 272 expression, together with the release of cytochrome c into the cytosol [34]. Collectively, 
273 these results support the notion that oral glycerol administration induces apoptosis in 274 preneoplastic livers and that the mitochondria is implicated in this phenomenon. Although 275 apoptosis may be initiated in any phase of the cell cycle, most cells undergo apoptosis 276 primarily in the G1 phase, indicating a direct connection between apoptosis and 277 proliferation. This relationship is explained by the presence of many cell cycle 278 regulators/apoptosis inducers such as p53, operating at the G1/S checkpoint [35]. 279 Consequently, it can be assumed that glycerol induces a cell cycle blockage in order to 280 favor the apoptotic process which would be its ultimate effect to reduce the foci 281 development.

282 After oral ingestion, glycerol is mainly taken up by the liver and converted into glycerol 283 phosphate by glycerol kinase. Once phosphorylated, it is mostly oxidized by glycerol-3284 phosphate dehydrogenase to dihydroxyacetone phosphate [27]. It has been demonstrated 285 that oxidation of glycerol phosphate induces mitochondrial ROS formation, both in normal 286 and in pathophysiological conditions. One of the main ROS generated during glycerol 287 phosphate metabolism is hydrogen peroxide, as demonstrated in isolated mitochondria from 288 different tissues, including hepatic tissue [29, 36]. The study of lipid peroxidation and 289 antioxidant enzymes activities showed that glycerol phosphate metabolism induces 290 production of ROS in our experimental model. Although hepatic levels of hydrogen 291 peroxide were not directly measured, the profile of changes in SOD and CAT activities 292 between the experimental groups supports the hypothesis that this molecule is primarily 293 being produced during glycerol treatment.

294 It has been established that metabolic hydrogen peroxide functions as a central hub in redox 295 signaling in major processes such as proliferation and cell death [37]. One link between 
296 oxidative stress signaling and proliferation/cell death processes is p53 induction by ROS.

297 Another possible connection is ROS-induced modulation of kinases such as JNK, Erk and

298 Akt. JNK signaling is activated in liver tissue of IPGly animals, supporting the well299 established role of ROS-induced JNK signaling in apoptotic cell death [38]. Despite we did 300 not observe any changes in activated Erk1 and Akt levels, Erk2 signaling is inhibited in

301 glycerol-treated rats. In line with this finding, it has been reported that glycerol has a 302 stimulating effect on the phosphatase activity that specifically induces Erk2 inactivation 303 [39]. Moreover, Erk activation is also required for G1/S transition via enhanced cyclin D1 304 synthesis [40].

305 A recent study of energy metabolism in HCC shows a depression of glycerol phosphate and 306 other energy metabolites concentrations within the tumor [41]. These data indicate that 307 tumor metabolism turns from mitochondrial oxidation to aerobic glycolysis. Furthermore, 308 based in the present findings, we hypothesize that tumoral cells attempt to avoid glycerol 309 phosphate accumulation as a strategy to evade the effects of this metabolite in their growth 310 rate.

\section{Conclusion}

313 Our results provide original data concerning the preventive actions of glycerol during the 314 early development of liver cancer. Our postulated mechanism is schematized in Fig. 8. 315 Briefly, glycerol is taken up by preneoplastic hepatocytes and converted into glycerol 316 phosphate. Then, glycerol phosphate undergoes oxidative metabolism inducing 317 mitochondrial oxidative stress generation. ROS act as intracellular messengers, producing 318 p53 activation and changes in JNK and Erk signaling. These phenomena induce cell cycle 
319 arrest and mitochondrial apoptotic cell death that finally conduct to a reduction of liver

320 lesions. Additional experiments using knockdown and knockout techniques might be useful

321 to confirm the proposed mechanism of action of glycerol in the initial development of liver

322 lesions.

323 This study is the first one to show a foci volume decreasing role of glycerol in the liver of

324 rats with hepatic preneoplasia. It is interesting to note that despite oral glycerol

325 consumption is innocuous and it is considered an "almost inert" molecule; glycerol exerts

326 its effects in a ROS-dependent manner, leading to cell cycle arrest and increased cell death.

327 The effect of glycerol administration on advanced stages of hepatic carcinogenesis is a 328 mandatory step in the study of glycerol anti-proliferative effects. The results presented in 329 this paper pave the way for a better understanding of natural and risk-free molecules that 330 applied in patients with liver chronic diseases, have the potential to decrease morbidity and 331 improve the quality of life for these patients. 
Ethical standards: animal studies were performed according to the NIH "Guide for the Care and Use of Laboratory Animals" (Publication no. 25-28, revised 1996) and approved by the local animal care and use committee (Permission 6060/234, Facultad de Ciencias Bioquímicas y Farmacéuticas, UNR).

Conflict of interest statement: The authors declare that they have no conflict of interest. 


\section{References}

1. Pagliaro M (2008) The future of glycerol : new uses of a versatile raw material. Royal Society of Chemistry, Cambridge

2. Quispe CAG, Coronado CJR, Carvalho Jr. JA (2013) Glycerol: Production, consumption, prices, characterization and new trends in combustion. Renew Sustain Energy Rev 27:475-493. doi: 10.1016/j.rser.2013.06.017

3. Ayoub M, Abdullah AZ (2012) Critical review on the current scenario and significance of crude glycerol resulting from biodiesel industry towards more sustainable renewable energy industry. Renew Sustain Energy Rev 16:2671-2686. doi: 10.1016/j.rser.2012.01.054

4. Lisenko KG, Andrade EF, Lobato R V., et al (2015) Metabolic parameters in rats receiving different levels of oral glycerol supplementation. J Anim Physiol Anim Nutr (Berl) 99:265-272. doi: 10.1111/jpn.12217

5. Patlar S, Yalçin H, Boyali E (2012) The effect of glycerol supplements on aerobic and anaerobic performance of athletes and sedentary subjects. J Hum Kinet 34:6979. doi: 10.2478/v10078-012-0065-x

6. Frank MS, Nahata MC, Hilty MD (1981) Glycerol: a review of its pharmacology, pharmacokinetics, adverse reactions, and clinical use. Pharmacotherapy 1:147-60.

7. Gwer S, Gatakaa H, Mwai L, et al (2010) The role for osmotic agents in children with acute encephalopathies: a systematic review. BMC Pediatr 10:23. doi: $10.1186 / 1471-2431-10-23$

8. Wiebe JP, Dinsdale CJ (1991) Inhibition of cell proliferation by glycerol. Life Sci 48:1511-7. 
9. Traudt CM, McPherson RJ, Studholme C, et al (2014) Systemic glycerol decreases neonatal rabbit brain and cerebellar growth independent of intraventricular hemorrhage. Pediatr Res 75:389-94. doi: 10.1038/pr.2013.236

10. Sugiyama N, Mizuguchi T, Aoki T, et al (2002) Glycerol suppresses proliferation of rat hepatocytes and human HepG2 cells. J Surg Res 103:236-42. doi:

10.1006/jsre.2002.6367

11. Maluccio M, Covey A (2012) Recent progress in understanding, diagnosing, and treating hepatocellular carcinoma. CA Cancer J Clin 62:394-9. doi:

10.3322/caac.21161

12. Su Q, Benner A, Hofmann WJ, et al (1997) Human hepatic preneoplasia: phenotypes and proliferation kinetics of foci and nodules of altered hepatocytes and their relationship to liver cell dysplasia. Virchows Arch 431:391-406.

13. Bannasch P (2012) Glycogenotic hepatocellular carcinoma with glycogen-groundglass hepatocytes: a heuristically highly relevant phenotype. World J Gastroenterol 18:6701-8. doi: 10.3748/wjg.v18.i46.6701

14. De Luján Alvarez M, Cerliani JP, Monti J, et al (2002) The in vivo apoptotic effect of interferon alfa- $2 \mathrm{~b}$ on rat preneoplastic liver involves bax protein. Hepatology $35: 824-833$.

15. Imai T, Masui T, Ichinose M, et al (1997) Reduction of glutathione S-transferase Pform mRNA expression in remodeling nodules in rat liver revealed by in situ hybridization. Carcinogenesis 18:545-51.

16. Casella ML, Parody JP, Ceballos MP, et al (2014) Quercetin prevents liver carcinogenesis by inducing cell cycle arrest, decreasing cell proliferation and 
enhancing apoptosis. Mol Nutr Food Res 58:289-300. doi: 10.1002/mnfr.201300362

17. Saltikov S (1967) A Stereological Method for Measuring the Specific Surface Area of Metallic Powders. In: Elias H (ed) Stereology. Springer Berlin Heidelberg, Berlin, Heidelberg, pp 63-64

18. Greenwell A, Foley JF, Maronpot RR (1991) An enhancement method for immunohistochemical staining of proliferating cell nuclear antigen in archival rodent tissues. Cancer Lett 59:251-6.

19. Pritchard MT, Malinak RN, Nagy LE, et al (2011) Early growth response (EGR)-1 is required for timely cell-cycle entry and progression in hepatocytes after acute carbon tetrachloride exposure in mice. Am J Physiol Gastrointest Liver Physiol 300:G112431. doi: 10.1152/ajpgi.00544.2010

20. Morita S, Ueda K, Kitagawa S (2009) Enzymatic measurement of phosphatidic acid in cultured cells. J Lipid Res 50:1945-52. doi: 10.1194/jlr.D900014-JLR200

21. Popov B, Gadjeva V, Valkanov P, et al (2003) Lipid peroxidation, superoxide dismutase and catalase activities in brain tumor tissues. Arch Physiol Biochem 111:455-9. doi: 10.3109/13813450312331342328

22. Ohkawa H, Ohishi N, Yagi K (1979) Assay for lipid peroxides in animal tissues by thiobarbituric acid reaction. Anal Biochem 95:351-8.

23. Tietze F (1969) Enzymic method for quantitative determination of nanogram amounts of total and oxidized glutathione: applications to mammalian blood and other tissues. Anal Biochem 27:502-22.

24. Donahue JL, Okpodu CM, Cramer CL, et al (1997) Responses of Antioxidants to Paraquat in Pea Leaves (Relationships to Resistance). Plant Physiol 113:249-257. 
25. Quiroga AD, Alvarez M de L, Parody JP, et al (2007) Involvement of reactive oxygen species on the apoptotic mechanism induced by IFN-alpha2b in rat preneoplastic liver. Biochem Pharmacol 73:1776-85. doi: 10.1016/j.bcp.2007.02.007

26. Lowry OH, Rosebrough NJ, Farr AL, Randall RJ (1951) Protein measurement with the Folin phenol reagent. J Biol Chem 193:265-75.

27. Lundquist F, Tygstrup N, Winkler K, Jensen KB (1965) Glycerol metabolism in the human liver: inhibition by ethanol. Science 150:616-7.

28. Tretter L, Takacs K, Hegedus V, Adam-Vizi V (2007) Characteristics of alphaglycerophosphate-evoked $\mathrm{H} 2 \mathrm{O} 2$ generation in brain mitochondria. J Neurochem 100:650-63. doi: 10.1111/j.1471-4159.2006.04223.x

29. Orr AL, Quinlan CL, Perevoshchikova I V., Brand MD (2012) A refined analysis of superoxide production by mitochondrial sn-glycerol 3-phosphate dehydrogenase. J Biol Chem 287:42921-42935. doi: 10.1074/jbc.M112.397828

30. Nemoto S, Takeda K, Yu ZX, et al (2000) Role for mitochondrial oxidants as regulators of cellular metabolism. Mol Cell Biol 20:7311-7318. doi: 10.1128/MCB.20.19.7311-7318.2000

31. Fabregat I (2009) Dysregulation of apoptosis in hepatocellular carcinoma cells. World J Gastroenterol 15:513-20.

32. Perkins ND (2002) Not just a CDK inhibitor: regulation of transcription by p21(WAF1/CIP1/SDI1). Cell Cycle 1:39-41.

33. Fabregat I, Roncero CC, Fernández M, Fern??ndez M (2007) Survival and apoptosis: A dysregulated balance in liver cancer. Liver Int 27:155-62. doi: 10.1111/j.1478-3231.2006.01409.x 
34. Correia C, Lee S-H, Meng XW, et al (2015) Emerging understanding of Bcl-2 biology: Implications for neoplastic progression and treatment. Biochim Biophys Acta - Mol Cell Res 1853:1658-1671. doi: 10.1016/j.bbamcr.2015.03.012

35. Chen J (2016) The Cell-Cycle Arrest and Apoptotic Functions of p53 in Tumor Initiation and Progression. Cold Spring Harb Perspect Med 6:a026104. doi: 10.1101/cshperspect.a026104

36. Jesina P, Kholová D, Bolehovská R, et al (2004) Glycerophosphate-dependent hydrogen peroxide production by rat liver mitochondria. Physiol Res 53:305-10.

37. Sies H (2014) Role of metabolic $\mathrm{H} 2 \mathrm{O} 2$ generation: Redox signaling and oxidative stress. J Biol Chem 289:8735-8741. doi: 10.1074/jbc.R113.544635

38. Shen H-M, Liu Z (2006) JNK signaling pathway is a key modulator in cell death mediated by reactive oxygen and nitrogen species. Free Radic Biol Med 40:928-39. doi: 10.1016/j.freeradbiomed.2005.10.056

39. Tonks NK (2013) Protein tyrosine phosphatases - from housekeeping enzymes to master regulators of signal transduction. FEBS J 280:346-378. doi: 10.1111/febs. 12077

40. Murphy LO, Smith S, Chen R-H, et al (2002) Molecular interpretation of ERK signal duration by immediate early gene products. Nat Cell Biol 4:556-64. doi: $10.1038 /$ ncb822

41. Beyoğlu D, Imbeaud S, Maurhofer O, et al (2013) Tissue metabolomics of hepatocellular carcinoma: tumor energy metabolism and the role of transcriptomic classification. Hepatology 58:229-38. doi: 10.1002/hep.26350 


\section{Figure legends}

Fig. 1 Effect of oral glycerol administration on number and volume of liver preneoplastic foci. (a) Representative images of rGST P-positive preneoplastic foci obtained by confocal microscopy (objective: 10X). (b) Changes in number of foci per liver and volume percentage of liver occupied by preneoplastic lesions are represented for IP and IPGly groups. IP: rats with liver preneoplasia; IPGly: IP rats treated with $200 \mathrm{mg} / \mathrm{Kg}$ body weight glycerol. Data are expressed as mean $\pm \mathrm{SEM} ; \mathrm{n}=6 .{ }^{*} p<0.05$ vs. IP

Fig. 2 Effect of oral administration of glycerol on the proliferative status of liver foci. (a) Representative images of proliferating cell nuclear antigen (PCNA)-positive cells obtained by optical microscopy (objective: 20X). (b) Changes in the proliferative index in the foci and the surrounding tissue. (c) Determination of the percentage of preneoplastic hepatocytes in each phase of the cell cycle. IP: rats with liver preneoplasia; IPGly: IP rats treated with $200 \mathrm{mg} / \mathrm{Kg}$ body weight glycerol. Data are expressed as mean $\pm \mathrm{SEM} ; \mathrm{n}=6$. $* p<0.05$ vs. IP

Fig. 3 Effect of oral administration of glycerol on the expression of cell cycle-related proteins. Western blot analysis of: (a) p53, (b) p21, (c) cyclin D1, (d) cyclin E, (e) cyclin A, (f) cyclin B1, (g) cyclin-dependent kinase $2(\operatorname{cdk} 2)$, and (h) cdk1. $\beta$-actin was detected as loading control. IP: rats with liver preneoplasia; IPGly: IP rats treated with $200 \mathrm{mg} / \mathrm{Kg}$ body weight glycerol. Densitometric analysis was performed and data are expressed as percentage of IP group (arbitrarily considered 100\%) and are mean \pm SEM; n =6 (a, b, c, $\mathbf{g}$ and h) or 4 (e and f). ${ }^{*} p<0.05$ vs. IP 
Fig. 4 Effect of oral administration of glycerol on apoptotic cell death. (a) Caspase-3 activity was determined in cytosolic fractions and expressed as percentages, being IP group arbitrarily considered as $100 \%$. (b) Mitochondrial levels of pro-apoptotic Bax and antiapoptotic Bcl-2 proteins were analysed by western blot. (c) After densitometric quantitation, $\mathrm{Bax} / \mathrm{Bcl}-2$ ratio was calculated, and results were expressed as percentage of IP group (arbitrarily considered as 100\%). Mitochondrial levels of pro-apoptotic (d) Bad and (e) PUMA proteins were also evaluated by western blot. (f) Release of cytochrome c was determined by western blot in cytosolic extracts from each experimental group. IP: rats with liver preneoplasia; IPGly: IP rats treated with $200 \mathrm{mg} / \mathrm{Kg}$ body weight glycerol. $\beta$ actin and prohibitin were probed as loading control in cytosolic and mitochondrial extracts, respectively. Data are mean $\pm \mathrm{SEM} ; \mathrm{n}=6(\mathbf{a}, \mathbf{b}, \mathbf{c}$ and $\mathbf{f})$ or $4(\mathbf{d}$ and $\mathbf{e}) .{ }^{*} p<0.05$ vs. IP

Fig. 5 Analysis of glycerol phosphate hepatic levels. Enzymatic detection of glycerol phosphate in liver homogenates was performed and corrected by protein concentration. IP: rats with liver preneoplasia; IPGly: IP rats treated with $200 \mathrm{mg} / \mathrm{Kg}$ body weight glycerol. Results are expressed as percentage of IP group (arbitrarily considered as 100\%) and are mean $\pm \mathrm{SEM} ; \mathrm{n}=6 . * p<0.05$ vs. IP

Fig. 6 Analysis of lipid peroxidation and liver antioxidant capacity. (a) Lipid peroxidation was determined by quantification of the amount of thiobarbituric acid reactive substances (TBARS). (b) Determination of reduced glutathione (GSH)/oxidized glutathione (GSSG) ratio in liver homogenates from the experimental groups. Analysis of (c) $\mathrm{Cu} / \mathrm{Zn}$ superoxide 
dismutase (SOD) and (d) catalase (CAT) activities in total liver homogenates. IP: rats with liver preneoplasia; IPGly: IP rats treated with $200 \mathrm{mg} / \mathrm{Kg}$ body weight glycerol. Data are expressed as percentage of IP group and are mean $\pm \mathrm{SEM} ; \mathrm{n}=6 .{ }^{*} p<0.05$ vs. IP

Fig. 7 Effect of glycerol treatment on activation of JNK, Erk and Akt signalling. Activated (phosphorylated) hepatic protein levels of (a) JNK1/2/3, (b) Erk1/2 and (c) Akt were determined by western blot analysis. Total levels of the kinases were also measured and phosphorylated/total kinase ratios were calculated. . IP: rats with liver preneoplasia; IPGly: IP rats treated with $200 \mathrm{mg} / \mathrm{Kg}$ body weight glycerol. Data are expressed as percentage of IP group and are mean \pm SEM; $\mathrm{n}=4$ (a) or 6 (b and $\mathbf{c}) .{ }^{*} p<0.05$ vs. IP

Fig. 8 Scheme showing the postulated mechanisms involved in the preventive action of glycerol in the early development of liver cancer. Inside the hepatocytes, glycerol is converted into glycerol phosphate. Then, glycerol phosphate undergoes oxidative metabolism and generates oxidative stress of mitochondrial origin. Reactive oxygen species (ROS) act as intracellular messengers, producing p53 activation and changes in JNK and Erk signaling activation. These phenomena induce cell cycle arrest and mitochondrial apoptotic cell death that finally conduct to a reduction of liver lesions. 
b
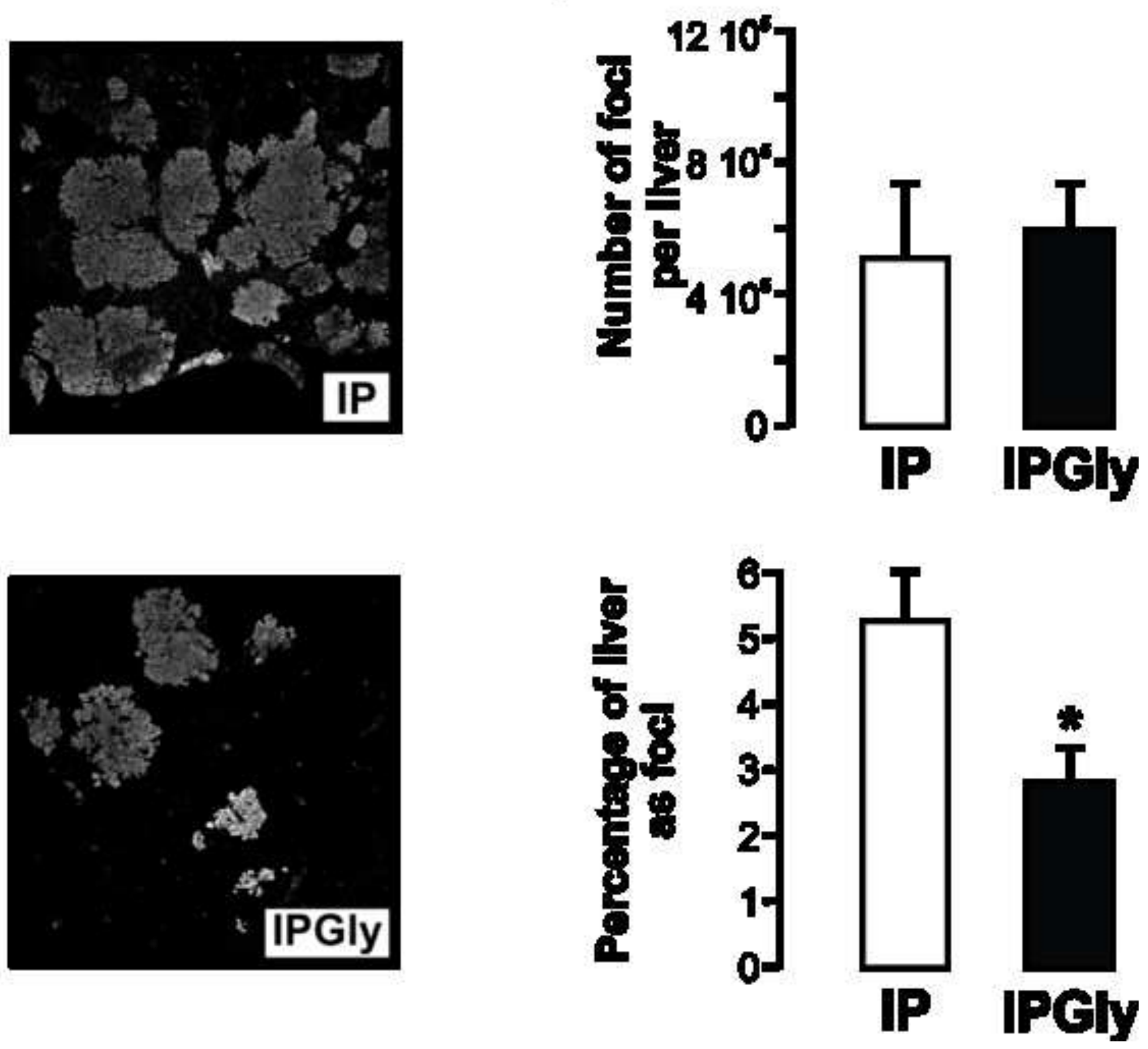
:
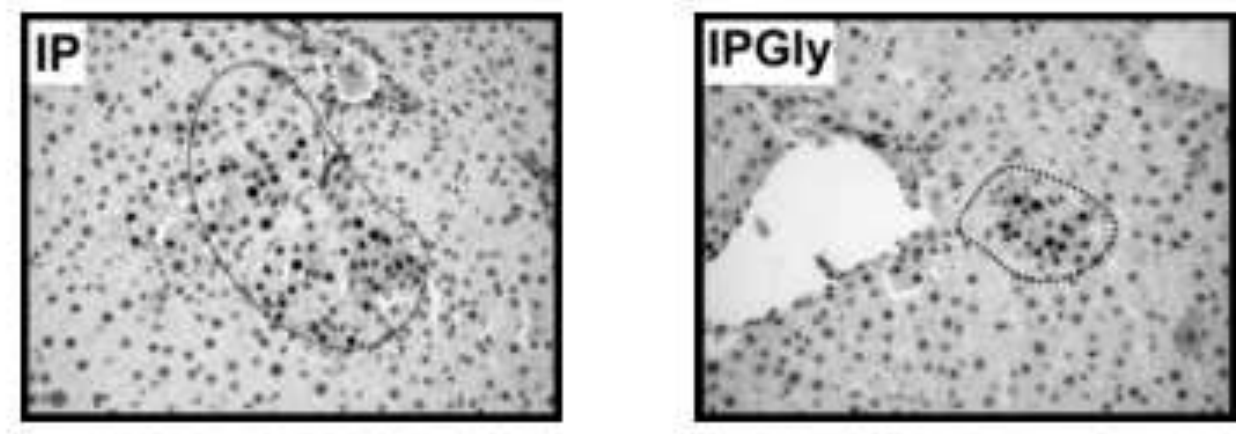

b

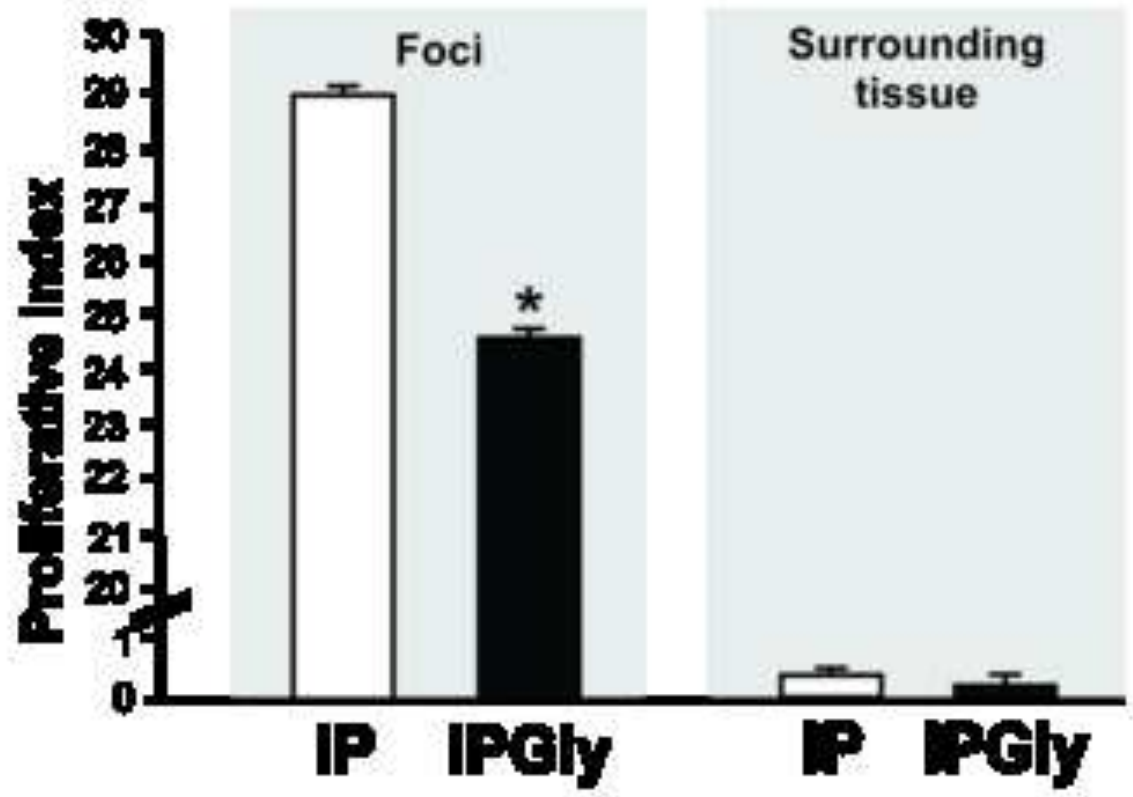

6
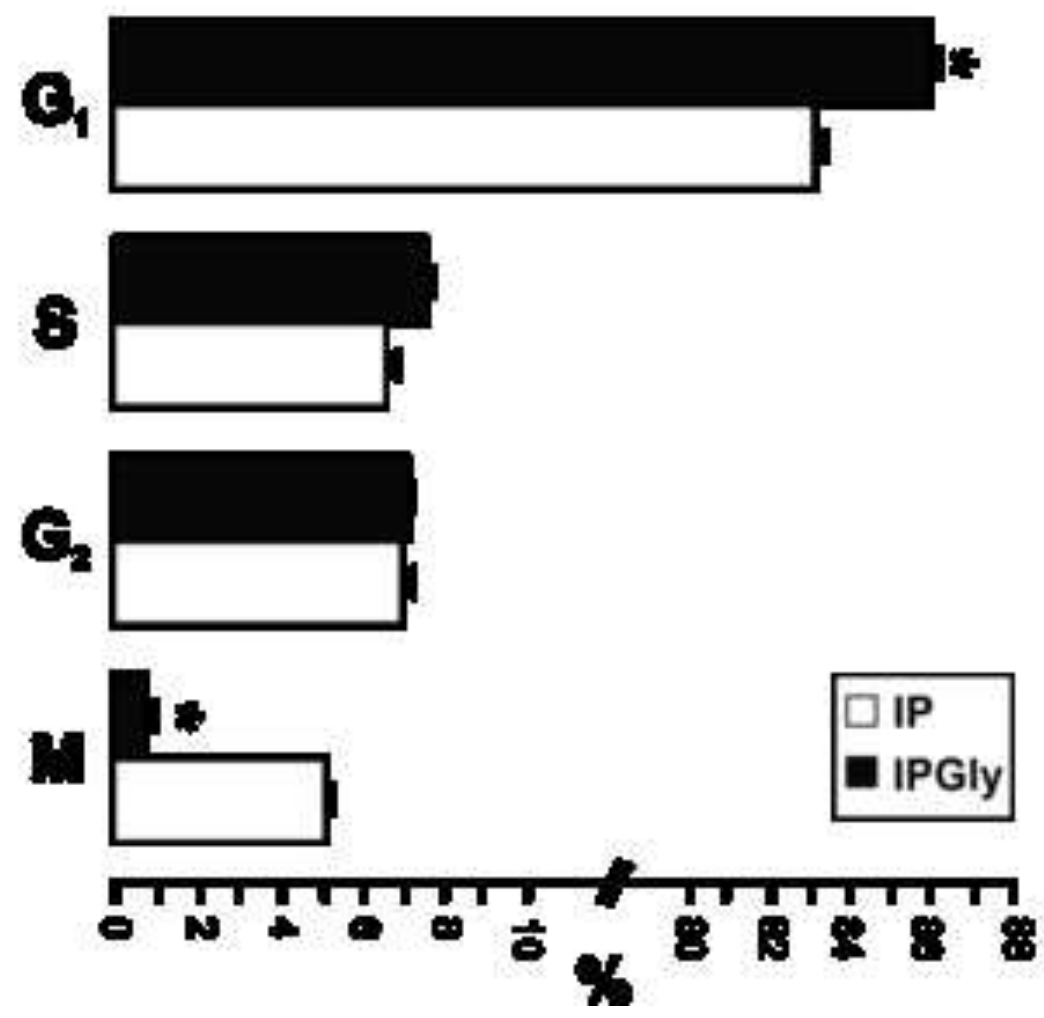
a

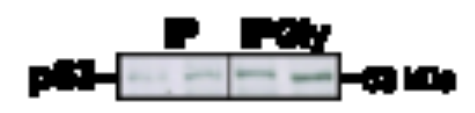

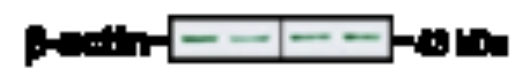

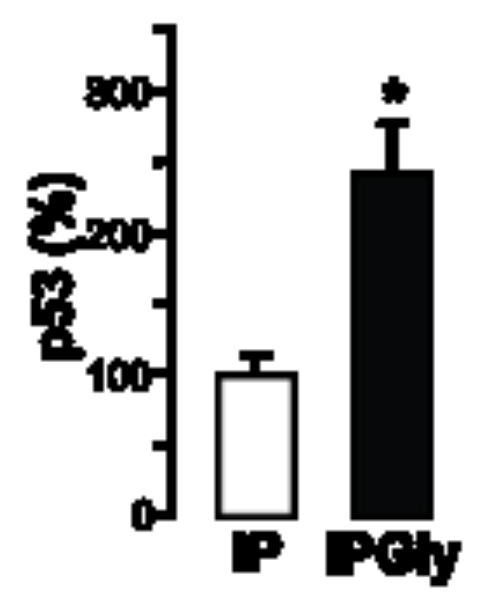

-

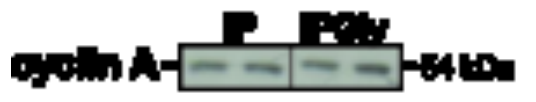

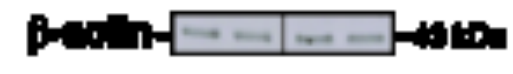

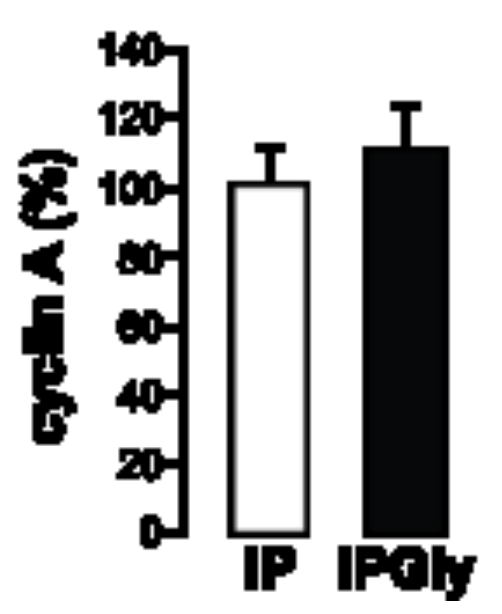

b

c

d

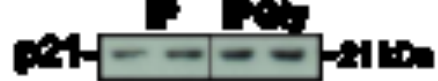

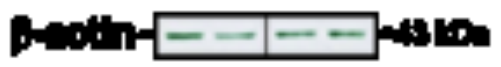

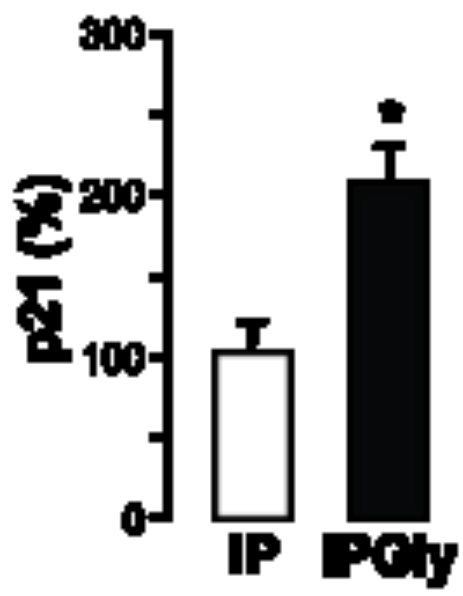

f

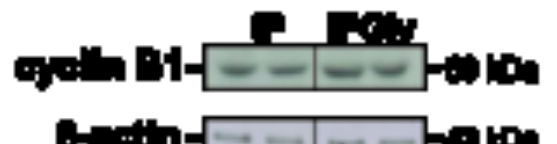

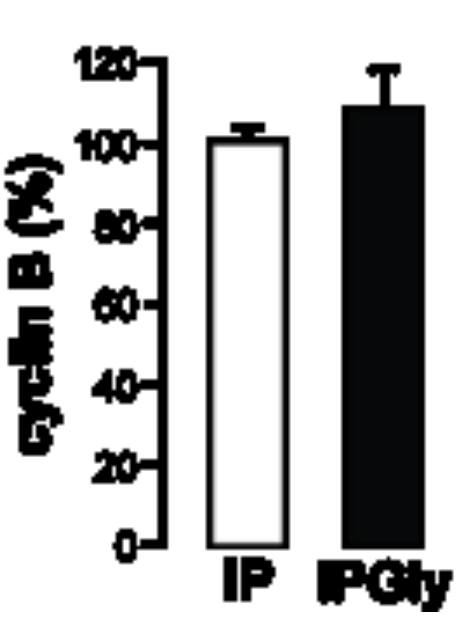

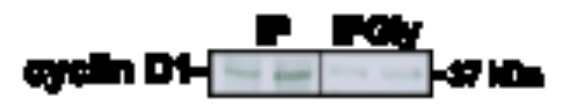

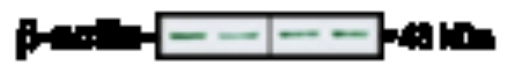

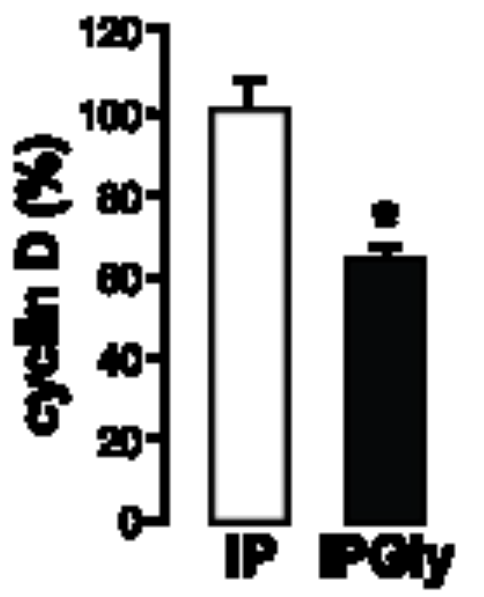

9
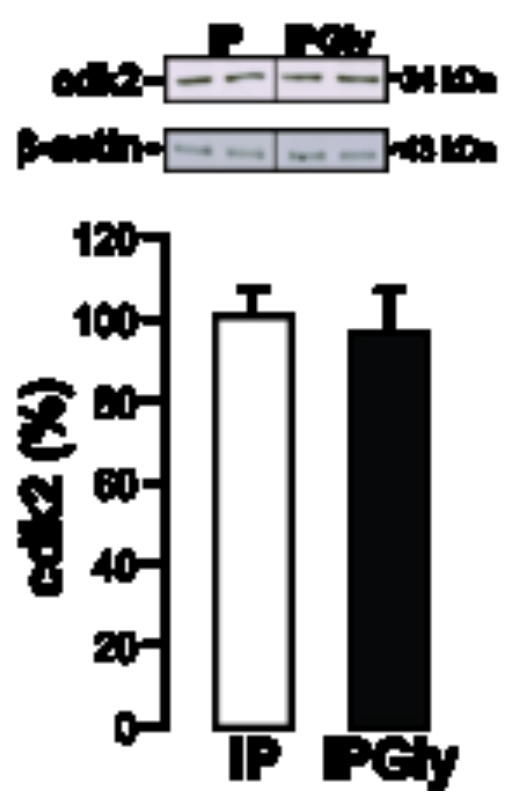

and

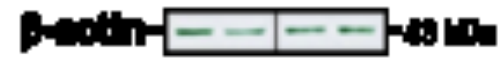

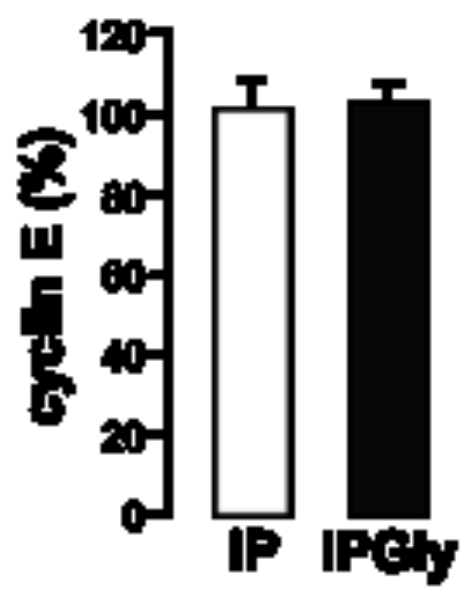

h

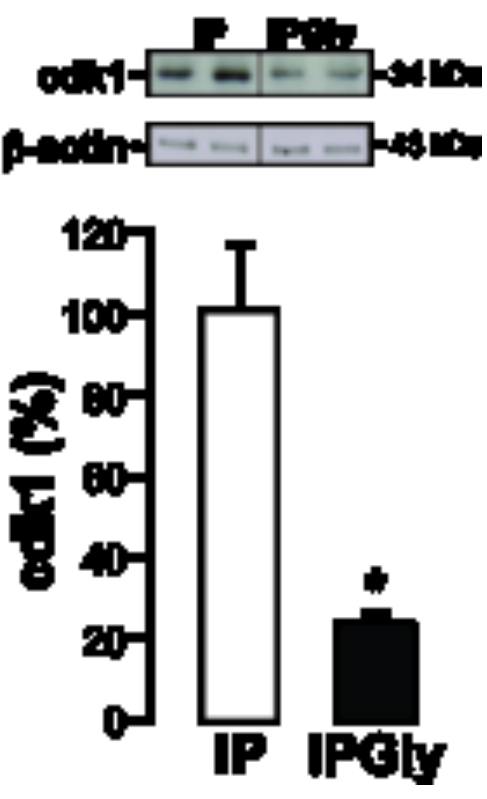




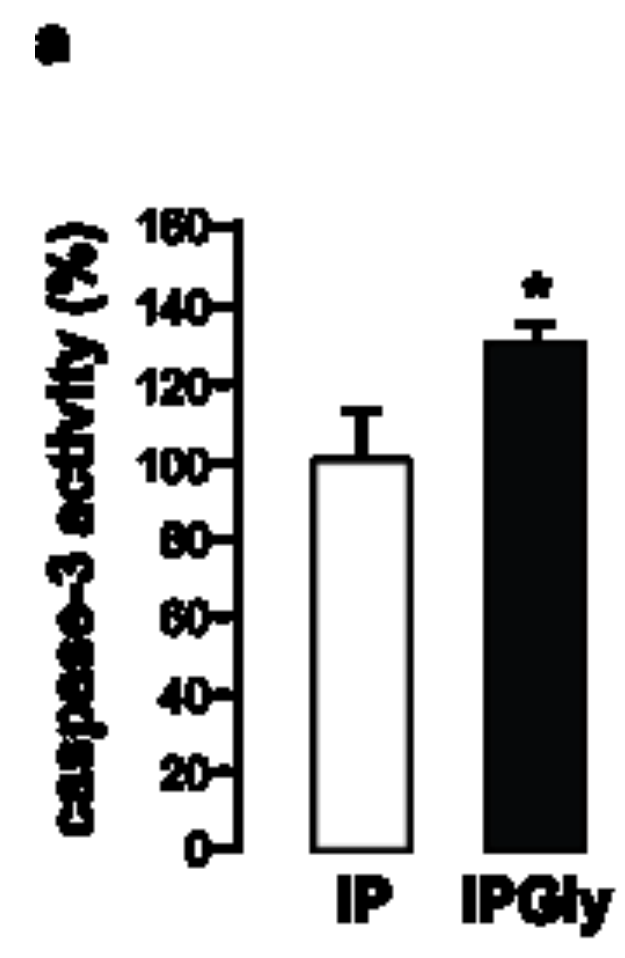

d
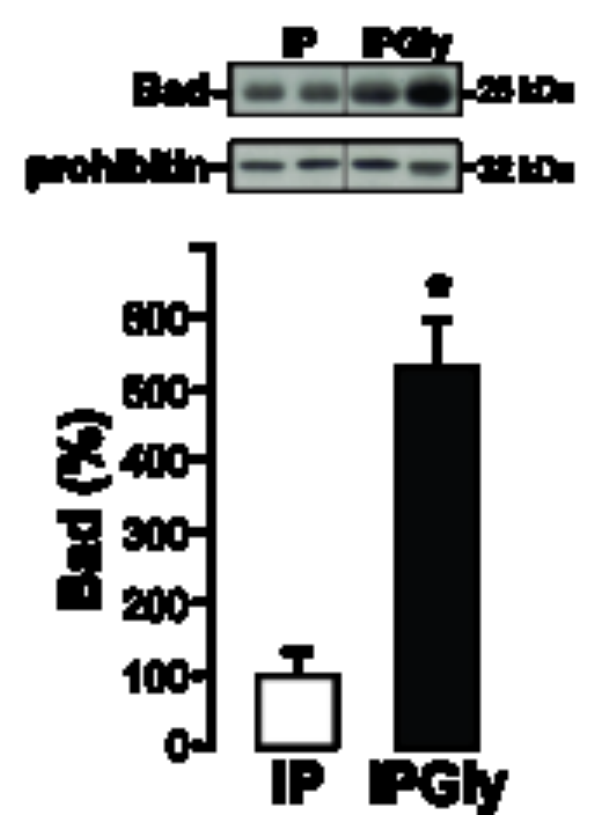

b

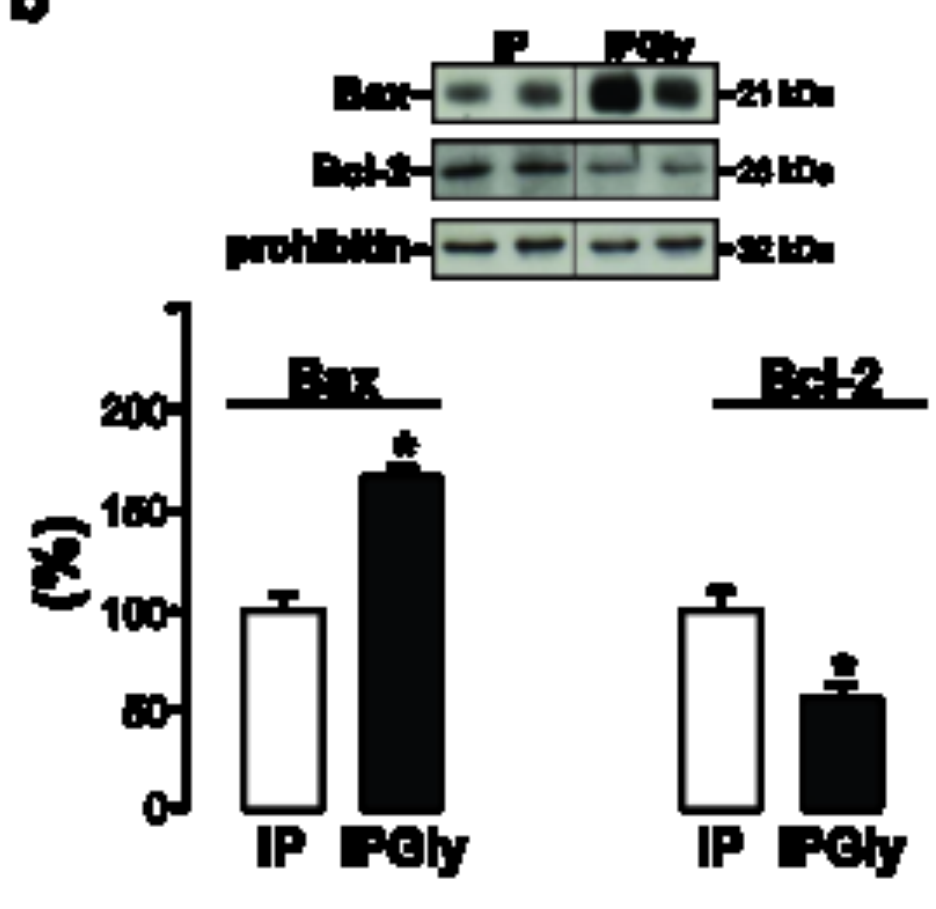

6
6

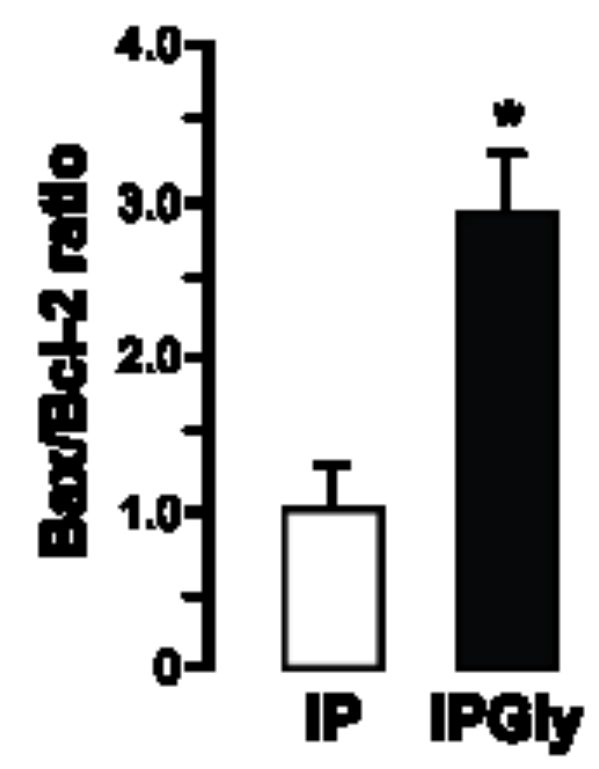

f
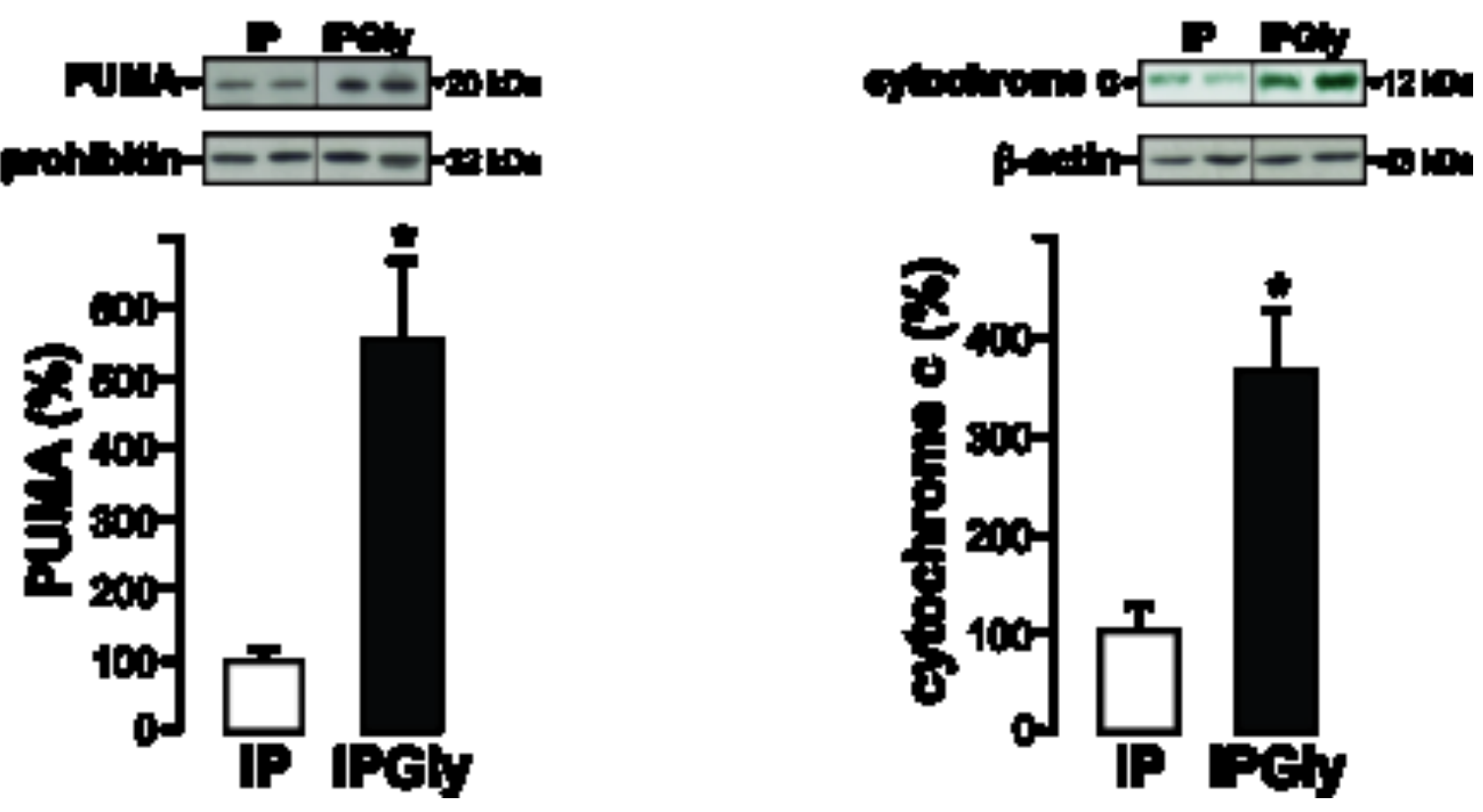

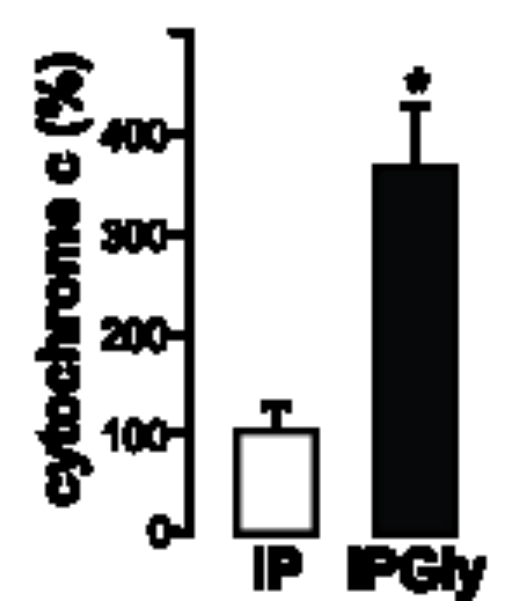




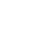

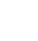

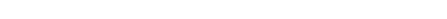

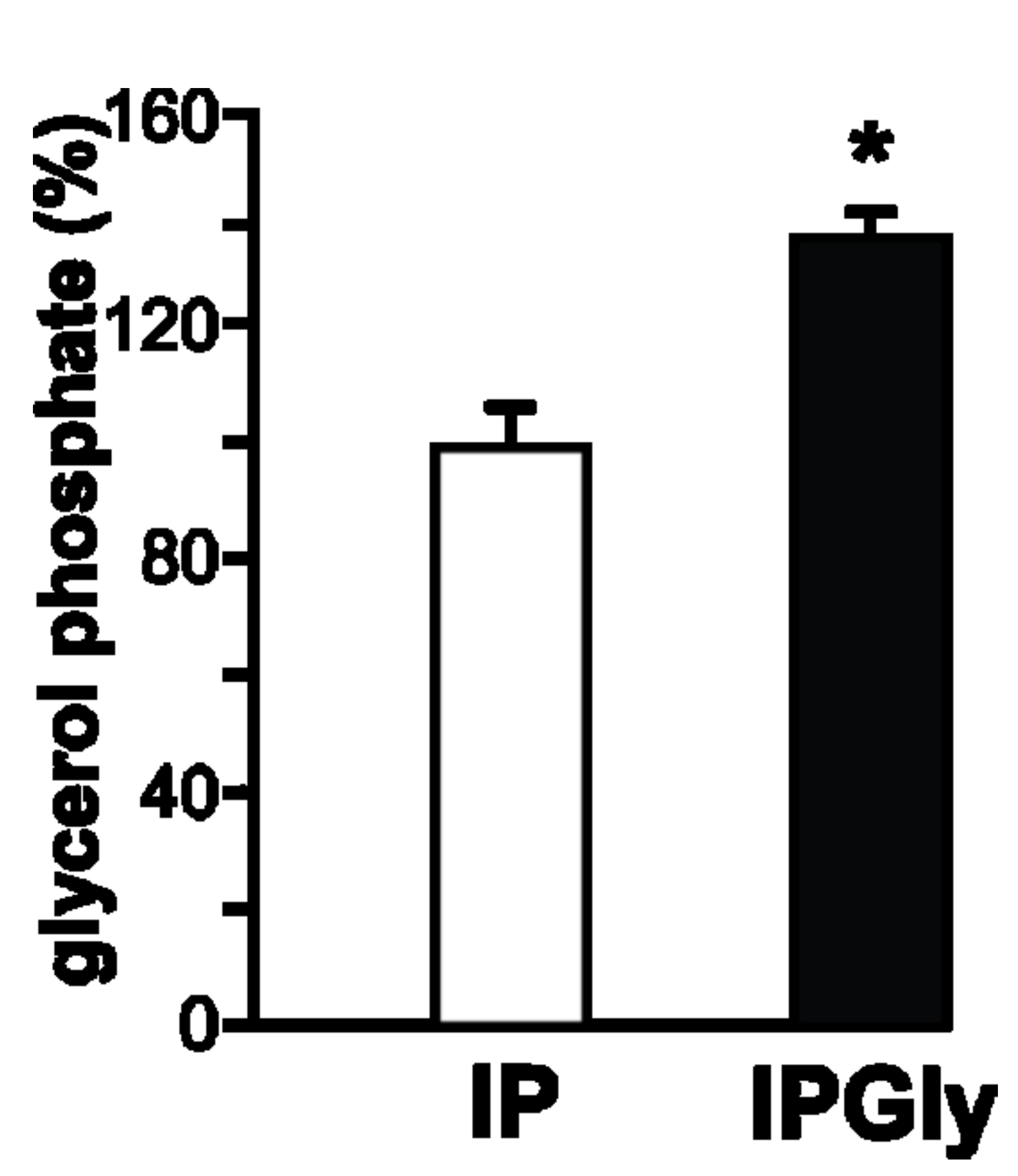

.




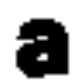

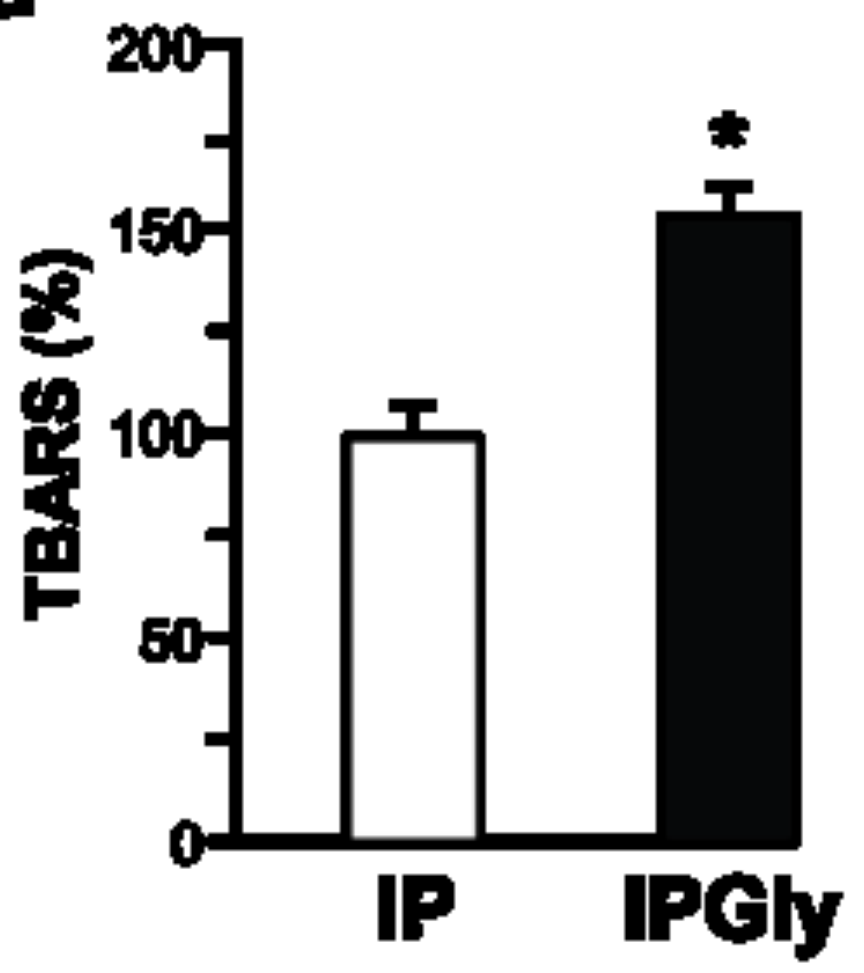

5

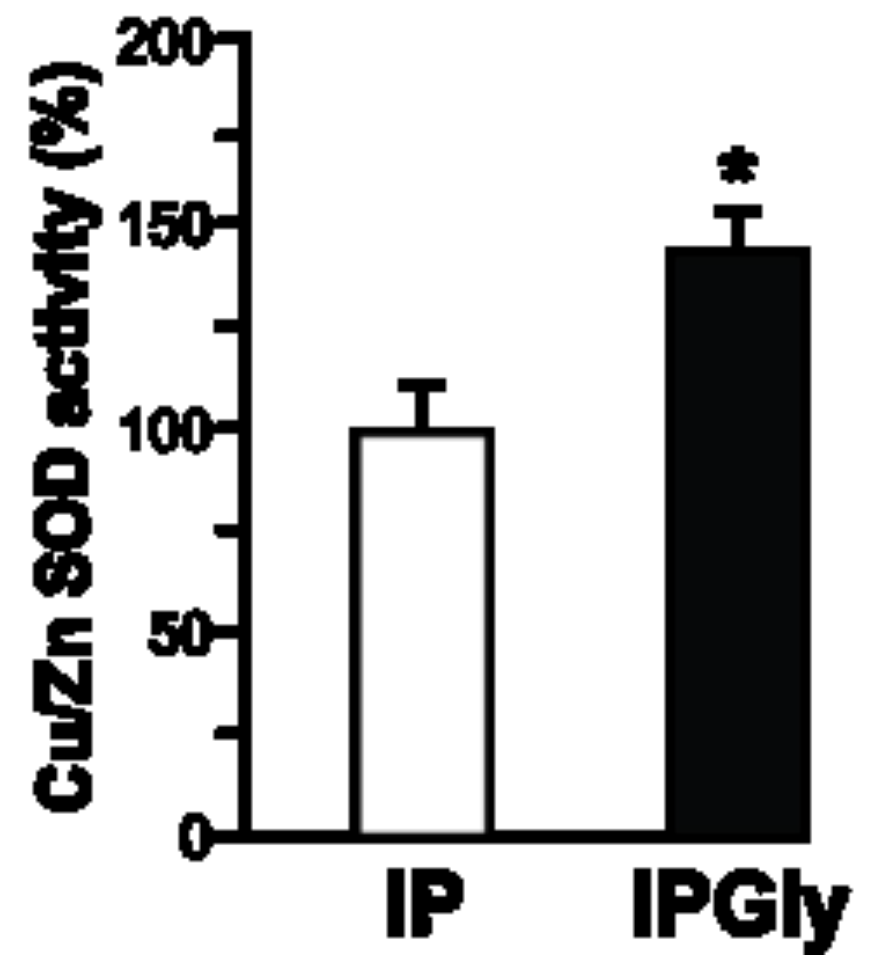

D

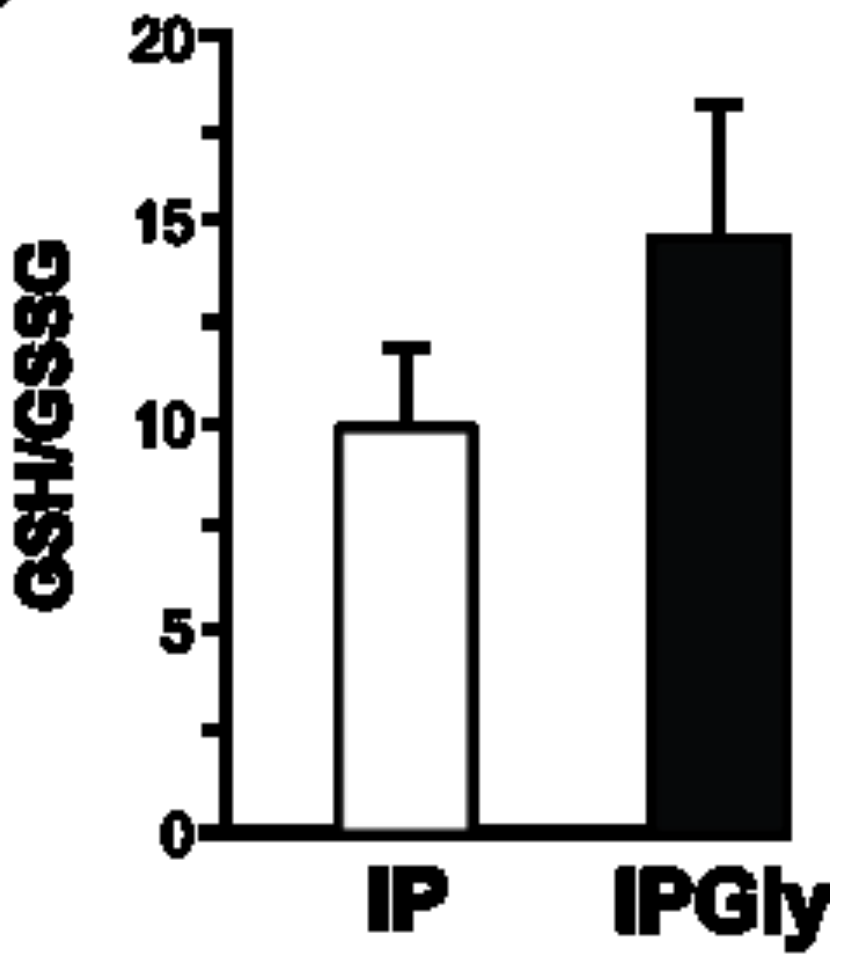

4

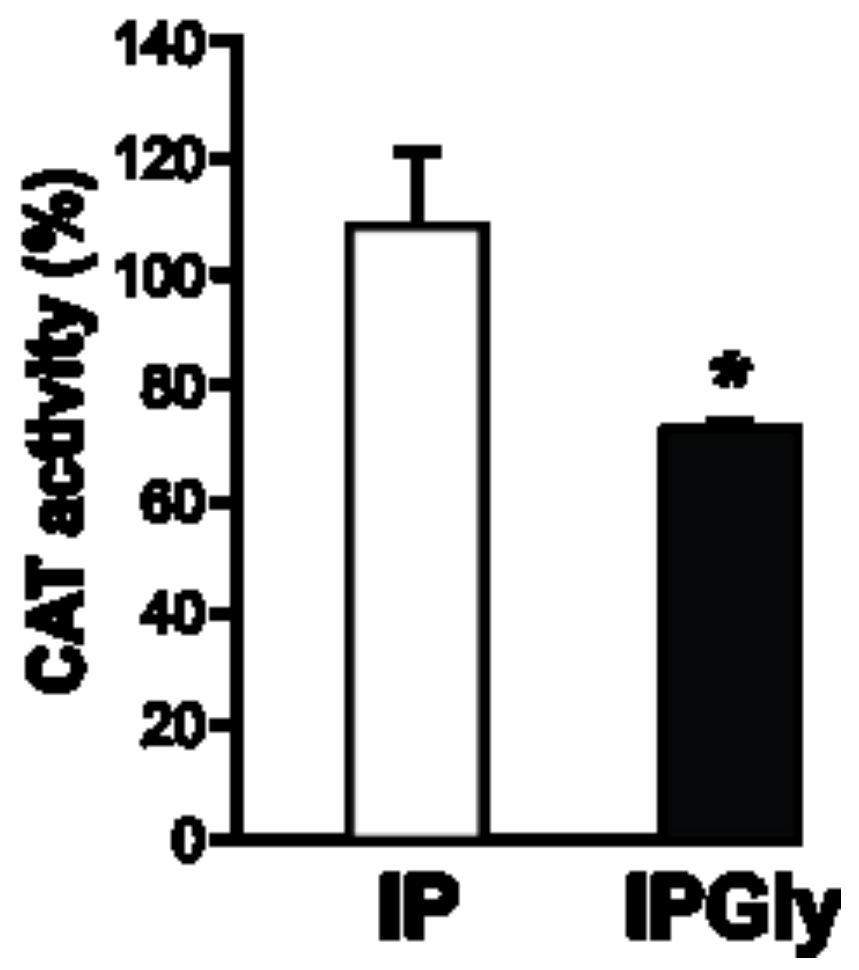


a

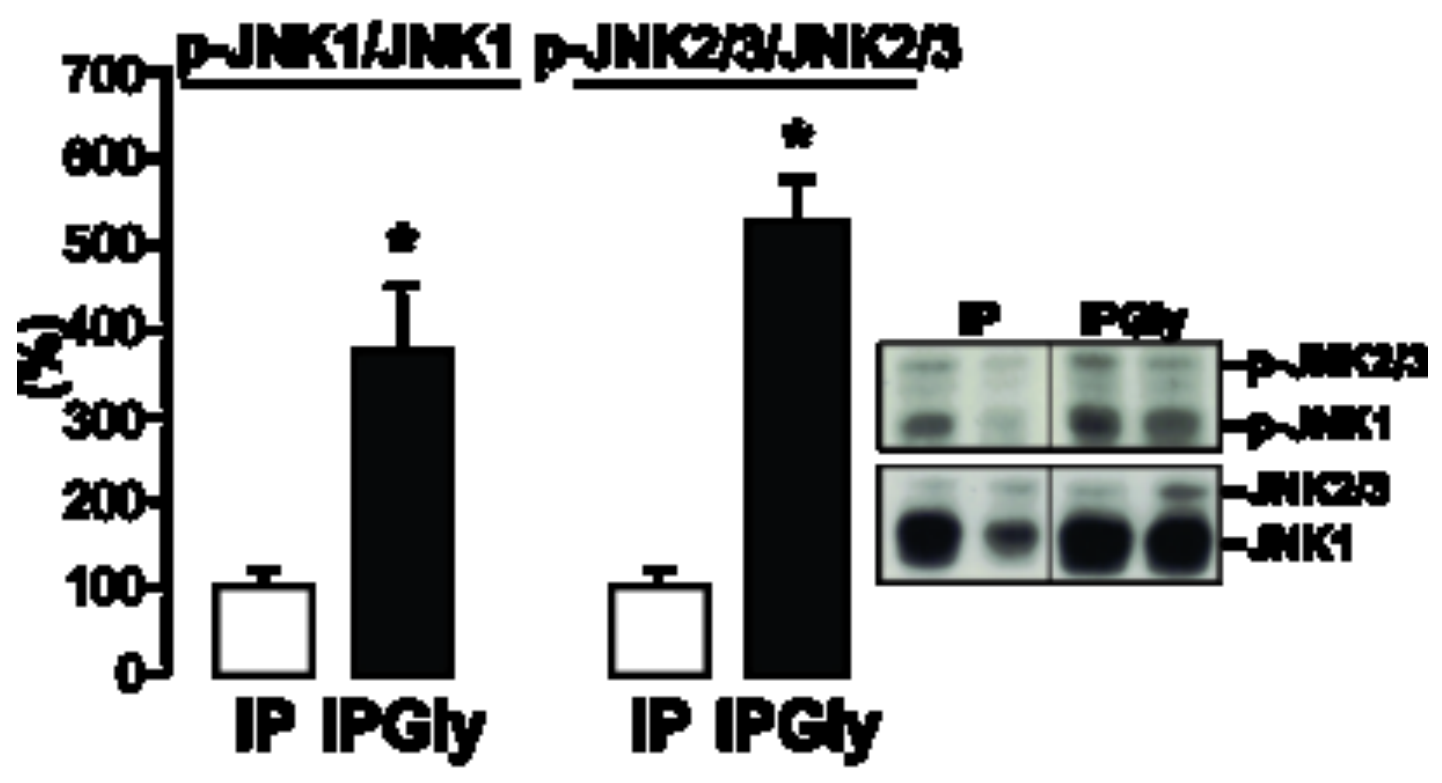

t)
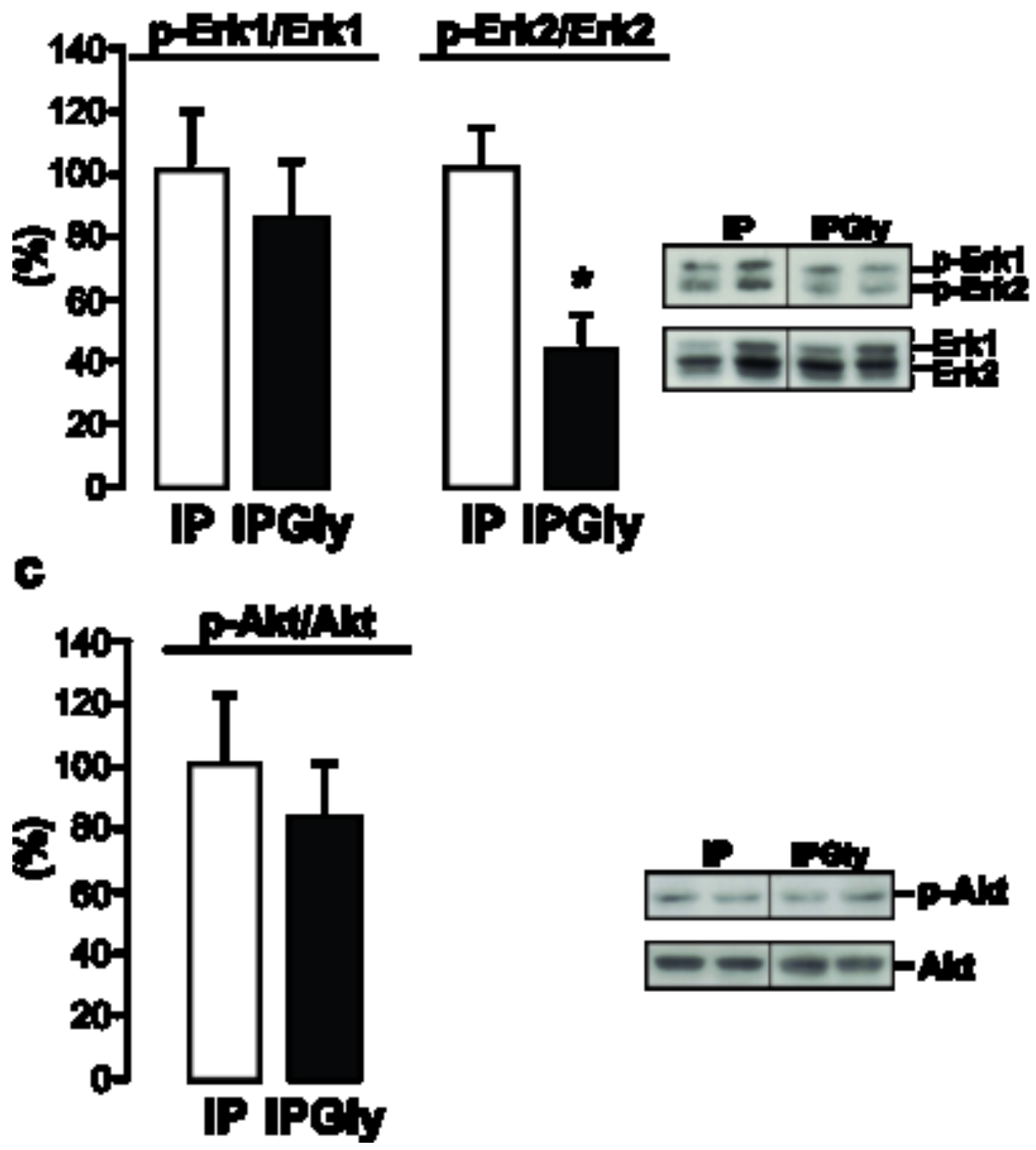


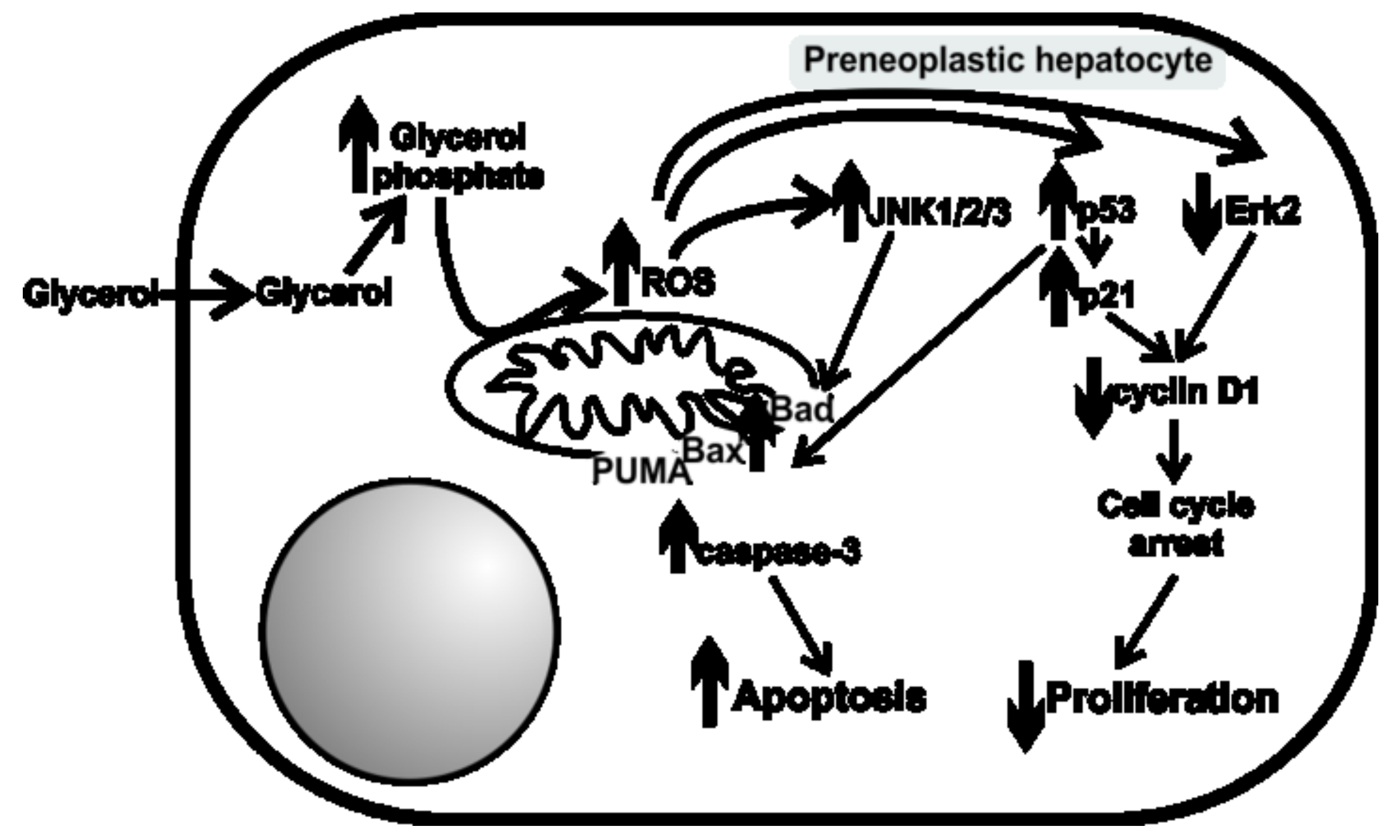


Electronic Supplementary Material

\section{Click here to access/download \\ Electronic Supplementary Material Supplementary Figure 1.docx}

